\title{
Margaret Funke Omidire* and Sameera Ayob The utilisation of translanguaging for learning and teaching in multilingual primary classrooms
}

\author{
https://doi.org/10.1515/multi-2020-0072
}

Received April 29, 2020; accepted December 7, 2020; published online December 24, 2020

\begin{abstract}
This article reports on the outcome of utilising a multilingual strategy that promotes translanguaging to support primary grade learners and the enablers and constraints of the implementation of such strategies. Purposive sampling was used to select two schools. Grade 5 and 6 learners $(N=162)$ and their teachers $(N=3)$ participated in the study. Qualitative research approach was employed and data was collected using classroom observations, semi-structured interviews, document analysis and storyboards. Data was analysed thematically and categorised. It was found that the enablers of translanguaging included a nonthreatening and safe environment. Teachers' positive attitude, the accessibility of the translated materials and the learners' sense of pride due to acknowledgement and use of their home languages during lessons. The constraints included inadequate resources, limited lesson time, complexity of some of the home languages, limited experience of the teachers using a multilingual approach and existing socio-economic factors. Future longitudinal research is required to explore the impact of the strategy on the academic performance of the learners.
\end{abstract}

Keywords: first langauge; multilingual classrooms; teaching and learning; translanguaging

\section{Introduction}

Multilingual classrooms are becoming common globally. Unfortunately, monolingual language-in-education policies still prevail resulting in language continuing to be a barrier to learning for many learners (Makalela 2018a). In South

\footnotetext{
*Corresponding author: Margaret Funke Omidire, Department of Educational Psychology, University of Pretoria, Pretoria, South Africa, E-mail: funke.omidire@up.ac.za. https://orcid. org/0000-0002-5784-7734
}

Sameera Ayob, Department of Educational Psychology, University of Pretoria, Pretoria, South Africa

ӘOpen Access. ( 2020 Margaret Funke Omidire and Sameera Ayob, published by De Gruyter. (c) BY This work is licensed under the Creative Commons Attribution 4.0 International License. 
Africa, which is the context of this study, the issues of language policies and practices, as well as the predominant socio-economic challenges are contributing factors affecting learners and teachers in multilingual classrooms. Proactive evidence-based support is needed to assist learners, teachers and schools with ways in which to rise above the challenges created by the lack of proficiency in the language of instruction.

Including the home language (L1) to enhance learning and providing support to learners in multilingual classrooms has gained momentum. Studies by García and Wei (2014), Makalela (2015b), and Mgijima and Makalela (2016) support the idea of integrating L1 into the learning environment and advocate for attempts to move away from imposed monolingual orientations in situations where multilingualism is widespread. The orientations that imposed a one language, one nation and one classroom ideology on multilingual learners, shifted towards building on multiple repertoires of languages to overlap. On a global platform the assimilation of multilingual practices in classrooms has shown encouraging academic achievement for learners (Blackledge and Creese 2010; Turner 2017; Vaish and Subhan 2015). More specifically "the concept of translanguaging has emerged giving space to the dynamic practices of multilingual people all over the world" (Garcia 2019, p. 370). Omidire (2019b, p. 4) endorses translanguaging "as a legitimate pedagogical approach involving the use of one language as a scaffold for language development and learning in another”. Duarte's (2019) study suggest that translanguaging strategies have provided learners and teachers in multilingual classrooms with flexible ways to utilize multiple languages to communicate, yet there is very little known on the execution of this approach in multilingual classrooms to enhance knowledge.

\section{The role of $\mathrm{L} 1$ in education}

Current research has shown the importance of the L1 as a resource for learning and is considered a good way to compensate for the challenges experienced by multilingual learners (Oihana et al. 2020; Omidire 2019b). Tian and Macaro (2012) maintain that learners who receive input in their L1 benefit more than learners who do not. Similarly, Cummins (2009) regards L1 as a foundation upon which new knowledge can be built. The use of L1 can have implications for learning because if learners cannot understand what is taught in the language of instruction, they will experience difficulties in progressing to the next level. Omidire (2019b, p. 5) states that "for learning to take place, there needs to be interaction between learners in the classroom and this could be facilitated by promoting the use of home languages to engage and make connections that lead to high-level comprehension". 
The argument presented here is that L1 needs a space in the educational environment so that learners can scaffold their learning (Hillman et al. 2019; Moody et al. 2019; Omidire 2019b, Smith et al. 2020). This is achieved by understanding the content being taught through their L1 (Makalela 2015b) and by allowing learners to navigate their learning through not relying fully on L1 but rather using it as a mediator to accommodate their learning experience (Daniel et al. 2019; Hillman et al. 2019; Makalela 2015a).

Oihana et al. (2020), Hurst and Mona (2017), and Ferreira-Meyers and Horne (2017) explain that the choice of language in education is still marginalised because L1s in schools are seen as drawbacks. These scholars elaborate that learners do not feel confident because they struggle to speak fluently in English. Additionally, findings from the study of Hurst (2016) elaborate that these learners feel sad that they have to relinquish their L1 and that their L1 is considered inferior. Meanwhile Lwanga-Lumu (2020) and Rivera and Mazak (2017) agree that integrating L1 could potentially lead to a greater sense of ownership within the learning process and foster a stronger sense of identity.

\section{Teachers position in multilingual classrooms}

Catalano and Hamann (2016) assert that English overpoweringly dominates the curriculum, despite the inherent diverse languages of the learners. This identifies the core problem of L1 being side-lined (Makalela 2018b) which compels the learners in classrooms to conform the use of English, limiting the flexibility in their choice of language (Makalela 2015b), restricting diversity, choice and suppressing ability. Oihana et al. (2020) encourage teachers to integrate multiple languages and move away from boundaries which tend to avoid using L1. Similarly, teachers' position in South African multilingual classrooms is multifaceted. Furthermore, Ticheloven et al. (2019) argue that teachers experiences become even more intricate in multilingual classrooms when learners speak languages that teachers are not familiar with. Omidire (2019b) emphasizes that teachers need to be flexible and open-minded of including L1 into classrooms as potential approaches to language teaching.

Teachers are significant role players in the classrooms and should adopt an accommodating approach to alter their teaching methods to scaffold the process of learning. García et al. (2017) position their thoughts on translanguaging from an educational perspective, and brought forth three components of translanguaging to be managed by teachers to enable and restructure translanguaging pedagogy. These include: stance, design and shifts. These scholars describe a teacher's stance as their beliefs and ideologies about emergent bilingual students and their language practices, in spite of the named language or variety. Design refers to how 
teachers set up affordances as they construct learning experiences for emergent bilinguals and shifts, would mean the moves a teacher makes in response to their learners (García et al. 2017).

Kleyn and García (2019) deliberate that the teacher's stance must include him/ her being cognisant of L1 of the learners and accept it as a resource to be used for learning, to eradicate past structures of hierarchy and power. These scholars explain design as how a teacher sets up facilities to support translanguaging in the classroom, and lastly, 'shift' places the needs of the learner as being important, it is this shift in mindset that allows the teacher to adapt to flexible strategies to promote learning and understanding (Kleyn and García 2019). Similarly, García and Leiva (2014) and Velasco and García (2014) advocate that a teacher must shift teaching practices towards accepting the intrinsic worth of dynamic language practices in education by liberating it.

\section{Movement towards translanguaging}

Translanguaging originated from the studies of Cen Williams (1994, 1996), a leading scholar in the 1980s, who used the term trawsieithu to describe a language practice that implied the planned and systematic use of two languages within the same lesson (Nagy 2018). Translanguaging seems to be a more flexible approach that allows multilingual learners to shuttle between languages in an innate manner (Phipps 2019). Translanguaging described by Garcia (2019, pp. 370-371) "is to educate all learners, regardless of their language practices, to maximize the meaning making, creativity and criticality of their educational experience". Garcia's (2009a, 2019) extensive work on translanguaging has expanded greatly where scholars in the field have used her initial discourse and embraced it as a novel way to support learners in multilingual classroom settings. Furthermore, Cenoz and Gorter (2017) distinguish between spontaneous translanguaging and pedagogical translanguaging, where spontaneous translanguaging is the use of languages both inside and outside school, while pedagogical translanguaging refers to the designed instructional strategies that integrate two or more languages. While education is a long-term process which impacts learners and educational outcomes throughout life (Bialystok 2018), Hillman et al. (2019, p. 43) points out that “teachers often use the students' L1 to build relationships, cultivate a shared identity, and create a positive classroom climate”. The value of learners' L1 is identified as an asset in education and has been influential on a global platform as a foundation for learning and development of knowledge (Omidire 2019b; Lasagabaster and García 2014). Similarly, Oihana et al. (2020) endorse that pedagogical translanguaging utilises a learners whole multilingual repertoire, and is regarded 
as a resource. Growing appeals from researchers (Childs 2016; Ferreira-Meyers and Horne 2017; Mwinda and van der Walt 2015) maintain that South Africans have been disadvantaged by linguistic dominance, where L1 is not recognized as the preferred language of instruction, despite being important for developing academic knowledge, critical and creative thinking, and confident identities (FerreiraMeyers and Horne 2017; Natri and Räsänen 2015). Owen-Smith (2010) reaffirms the value of L1 as being a way for learners to be given the opportunity to perform to the best of their ability and reach their full potential.

Garcia (2009b) has broadened the concept to include multiple discursive language practices a multilingual person engages in at school, the street and beyond to formulate and express thoughts to make sense of the world. In line with Cenoz and Gorter's (2017) view on pedagogical translanguaging, it is appropriate to deduce that translanguaging creates a space for the use of two or more languages inside one lesson with the aim to support learners to learn and understand through interactional communication with the teacher and their peers.

\subsection{Enablers and constraints for utilising translanguaging}

Baker (2011) identifies four educational advantages of translanguaging. This includes: to promote a deeper and fuller understanding of translanguaging as a support strategy; to help the development of parallel language; to facilitate home-school links and co-operation and to help the integration of fluent speakers with early learners. Furthermore, Garcia et al. (2017) highlights that translanguaging can create a classroom environment where learners challenge linguistic hierarchies; and simultaneously allow learners to feel like valued members of the classroom community, enabling them to use all of their resources to participate fully in class activities. Canagarajah (2011) and Paxton (2009) support this approach in that it will give learners a voice to better position, improve and organise future pedagogical practices that can contribute to equality in education. Supporting teachers in multilingual classrooms by adopting strategies to enable learners to maximise their opportunities to learn (Omidire 2019b) has become a priority.

García and Wei (2014) articulate that even though it is important to put the minority language alongside the majority language, ensuring it has a place in powerful domains. It is important to preserve a space, not a rigid or static place, in which the minority language does not compete with the majority language. Strauss (2016) draws attention to the majority of parents who would rather have their children be taught through the medium of English, discarding L1 as a resource within African languages. Meanwhile Madiba (2012) and Jaspers (2018) indicate that translanguaging is not beneficial to some learners who find it as not being liberating. 
Omidire (2019a) additionally expressed that the constraints of translanguaging practices include teachers not having sufficient training to deal with second language learning, nor can they adjust the curriculum to support their teaching due to time constraints especially in large classrooms (Khong and Saito 2013). Teachers find it difficult to include support strategies for their learners as there are insufficient resources at many of the schools (Balfour et al. 2008) which influence learners' schooling.

The conceptual framework utilised in our study was Lev Vygotsky's (1962) Socio Cultural Theory (SCT), highlighting concepts like mediation, zone of proximal development (ZPD) and scaffolding. Furthermore, Kretzman and McKnight's (1993) assets-based approach highlighting resources, abilities, skills and assets within the framework of positive psychology were recognized as foundational base for the study. The ZPD, scaffolding, and mediation allow learners to learn under guidance and in collaboration with peers for guided assistance provided to support the learners' current competence complementing and building on their existing abilities (Cole and Cole 2001). Once the learners familiarize themselves with the content, and begin to link L1 to fill in the gaps in L2, there is mastery of task as stimulated by Vygotsky (1962). Mediated learning is guided by technological processes like translated audio recordings of learners L1 which puts translanguaging theory into practice by implementing multiple languages to inform learning. Furthermore, the social context is important as it enables a space which encourages dialogue between the teacher and the learner, as well as between the learners to ascertain collaboration, communication, and constructing knowledge in multilingual classrooms. The asset-based approach illuminates L1 as an asset to be used for learners to make meaning of content learnt in the classroom, encouraging more than one language to be practiced inside multilingual classrooms promoting translanguaging in practice.

\section{The purpose of the study}

The purpose of this study was to explore the enablers and constraints of using learners' home languages as a support strategy to facilitate learning and teaching within multilingual classrooms and thereby developing both L1 and the English language within the framework of additive multilingualism. The study sought to gain a comprehensive understanding of how teachers manage translanguaging in their classrooms and how learners in multilingual classrooms learn by using L1 to facilitate the learning process. The research question guiding the study was: What are the enablers and constraints of using translanguaging in primary school classes? 
To answer this research question, a qualitative approach was applied to be able to find out what happened in classrooms in terms of how teachers and learners approached the use of multiple languages during lessons and simultaneously observed their attitudes, skills and experiences.

\subsection{Setting and participant selection}

Two schools located in Gauteng, South Africa were selected. Each school was selected on the basis that it met the criteria for inclusion such as being multilingual, accessibility and majority of the learners have IsiZulu and Sepedi (also known as Sesotho) as their L1 and the language of instruction is English. Two grades from each school (Grades 5 and 6) and two classes per grade. A total of three teachers and 162 learners participated. Table 1 highlights the participants details. Learners from both schools come from communities with high levels of poverty and unemployment. Most learners L1s are either isiZulu or Sepedi, however some learners come from neighbouring African countries and these learners and some teachers have a different L1. Language proficiency is a significant challenge and most learners struggle to communicate in English. Additional challenging features included: overcrowded classrooms of more than 40 learners per classrooms, inadequate infrastructure and classroom resources.

Table 1: Details of learners.

\begin{tabular}{|c|c|c|c|}
\hline \multirow{2}{*}{\multicolumn{2}{|c|}{$\frac{\text { School A }}{\text { Two Grades }}$}} & \multicolumn{2}{|l|}{ School B } \\
\hline & & \multicolumn{2}{|l|}{ Two Grades } \\
\hline Grade 5 & Grade 6 & Grade 5 & Grade 6 \\
\hline Grade & Grade & Grade & Grade \\
\hline 5 & 6 & 5 & 6 \\
\hline No. of learners & No. of learners & No. of learners & No. of learners \\
\hline 40 & 42 & 40 & 40 \\
\hline \multicolumn{2}{|c|}{ Total number of learners $=82$} & \multicolumn{2}{|c|}{ Total number of learners $=80$} \\
\hline
\end{tabular}

L1s spoken by majority of the learners

\begin{tabular}{|c|c|c|c|}
\hline English, Sepedi, isiZulu & $\begin{array}{l}\text { English, Sepedi, } \\
\text { isiZulu, isiXhosa }\end{array}$ & English, Sepedi & $\begin{array}{l}\text { English, Sepedi, } \\
\text { isiZulu, Urdu }\end{array}$ \\
\hline
\end{tabular}

Additional L1s spoken by a few learners

\begin{tabular}{ll}
\hline isiZulu, Venda, Xitsonga & isiZulu, Venda, \\
Urdu
\end{tabular}




\subsection{Data collection methods}

Semi-structured interviews, classroom observations, teachers' observation feedback sheet and storyboards were used as data collection methods. Semi-structured interviews were conducted by one of the researchers at both schools before and after the data-collection process. The initial semi-structured interviews were with the school principals, the head of departments and the three teachers involved in the study to understand the current practices and common challenges in multilingual classrooms, the strategies used to cater for these learners, followed by their perception of translanguaging as a practice and its effectiveness and/or ineffectiveness thereof. All interviews were recorded and transcribed. Classroom observations were conducted using video and audio recording equipment bin an unobtrusive way in order not to disrupt regular classroom activity. The recordings were supplemented by observational notes taken by the researchers. Observations included aspects such as: how the lessons were conducted, how the multiple languages were simultaneously included in the lesson, the teachers' techniques, the learners' reactions and participation during the lessons being conducted. Teachers additionally used their observations sheets to capture how they perceived the learners in both the regular and the support implementation classrooms, to reduce any unintentional bias on the side of the researchers (Nieuwenhuis 2010). The storyboard was included to understand how the learners experienced multiple languages and their experiences listening to comprehension texts in their L1. Guillemin (2004) explains that drawings encourage collaborative meaning-making by giving voice to what the drawing was intended to convey. An inductive thematic analysis interpreted the raw data gathered and was prepared using transcription (Hayes 2011), and coded to define significant themes and subthemes.

\subsection{Strategy implemented}

The strategy involved introducing and integrating learners home languages (in this case Sepedi and isiZulu) to the teaching and learning process in addition to English which was the language of instruction, Passages/stories from the learners' English textbooks were translated into isiZulu and Sepedi. These translations were then audio recorded and printed. This meant that an English passage was translated by translators, printed as a hard copy and was pre-recorded in the specific L1s of the learners. The translated audio recordings were played during the lesson and hard copies of the translated texts in multiple languages (English, Sepedi, isiZulu) 
Table 2: Data collection process.

\begin{tabular}{c}
\hline Support implementation classroom \\
\hline Utilizing the English period at school \\
Choosing a comprehension text from the prescribed book (English) \\
\hline
\end{tabular}

Translating the text into both Sepedi and IsiZulu and having it pre-audio recorded.

Text in English, printing translated IsiZulu and Sepedi text Text in English only.

Hand out the English, IsiZulu and Sepedi (translated texts) Hand out only the English text to to the learners. the learners.

The teacher teaches the class by either reading or asking the learners to read the text in English The translated audio recordings of the English text are played in both Sepedi and IsiZulu

The learners are encouraged to look at the translated text handouts in front of them, and listen to the translated audio recording being played.

The teacher then asks the learners to answer the questions that follow in the prescribed book by writing them down on worksheets provided.

were accessible to all learners during the lesson. This promoted the idea of the same learning content being presented in multiple languages simultaneously.

The outline of the data collection process followed both the regular and the support implementation class on Table 2.

\section{Findings}

\subsection{Enablers of translanguaging}

We found that the enablers of using translanguaing identified by the participants included, a non-threatening and safe environment, teachers' positive attitude towards translanguaging, the availability of translated audio recordings as a resource and valuing L1 in the classroom facilitates better understanding as projected from the interviews, observations and storyboards of the individual learners.

\subsubsection{A non-threatening and safe environment}

The research demonstrated that providing multiple languages into one lesson plan worked well and was met with phrases and words like "benefited the learners", 
“enjoyment”, and "better understanding” when translanguaging was taking place which is in line with Wei's (2011) observation centred in the process of learning and teaching to incorporate making meaning. From the teachers' observation sheets and the transcripts of semi-structured interview, they reported that the learners felt included when they heard their L1's being used in the classroom which supported them positively in that there was more engagement during the lesson, they were able to understand the meanings of words they previously did not know, and that they seemed comfortable while the support strategy was being implemented. This is in line with Garcia et al. (2017) where they stress that translanguaging enables learners to feel accepted into the classroom community which in turn promotes the use of all their resources to participate fully. Mgijima and Makalela's (2016) work illustrated the positive effects of what enables translanguaging to be effective, these included meaning making created by learners, the safe environment within which learners could experiment with their L1 and L2 language in a nonthreatening way, as well as collaboration and association amongst the learners. By including learners from similar contextual backgrounds together with the same L1's, into a classroom space with teachers they know created a non-threatening environment which enabled translanguaging as a practice to take place. A similar view is reiterated from Leask (2019), who accepts that enabling language learning in multilingual classrooms requires a specific social environment, school culture, and an instructional classroom to integrate and support learners by creating innovative ways for them to achieve academically.

A Storyboard from a learner articulated the following:

- "I enjoyed listening to the story in Sepedi more better"

- "I feel more free and I was like I am home listening to my mother telling me a story"

The learner drew a picture of a mother reading a story to a child in a bubble to demonstrate the strong link to feelings being elicited when L1 is brought into the classroom. Storyboard 1 below associated it to his/her home as quoted, "I felt I was at home" and additionally accentuated the need for more tranlanguaging lessons to support his/her understanding as quoted:

- "Yes, I would like more lessons because I understand"

\subsubsection{Teachers positive attitude towards translanguaging}

The teachers facilitated the classroom by probing the learners with questions related to the comprehension texts. Bialystok (2018) and Ismaili (2015) maintain that teachers in diverse linguistic settings need to have a positive attitude to create a harmonious classroom environment. Storyboard 2 identified the teacher as a role model. 


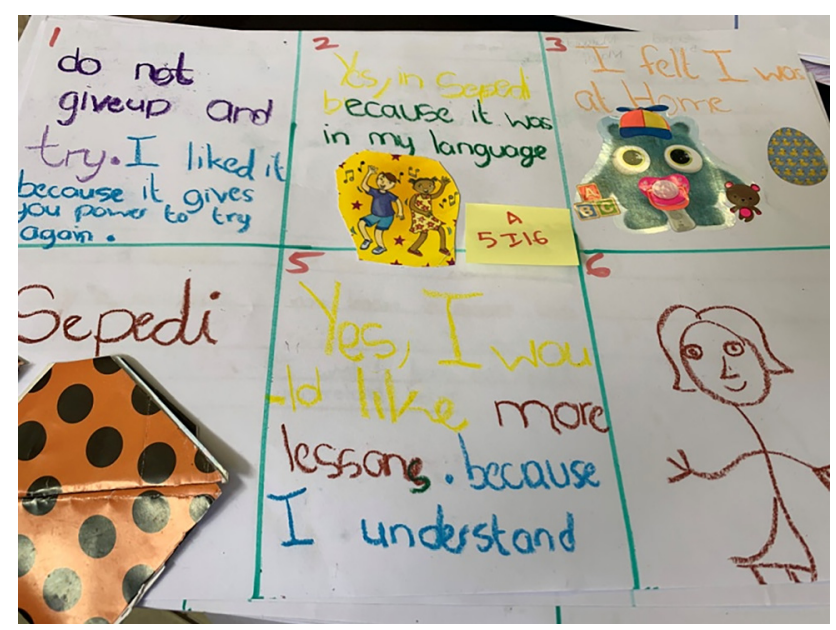

Storyboard 1: Demonstration of attitude.

- "I felt very happy to hear an English story and change it to Zulu language"

- "Yes, because it's my home language and I really love stories with Zulu language"

The teacher's engagement of interacting with the learners during the lesson enabled the translanguaging support strategy to meet its outcome. This led to teachers concurring that translanguaging strategies impact the classrooms positively because the learners were able to scaffold their learning by using L1 which is already a resource in their life world and apply it to them formulating direct links of understanding content being taught in the classroom. In line with one of Sarker's (2019) processes which meaningfully scaffold learners' experiences.

\subsubsection{The availability of translated audio recordings as a resource}

The teachers' observations in relation to the translated audio recordings allowed most learners to simultaneously follow the story and this was captured when the learners concurrently continued to turn the pages to follow the story. This act describing translanguaging as "the planned and systematic use of two languages within the same lesson" (Nagy 2018, p. 42) is captured. The audio recordings provided a platform which enabled better understanding and generated more confident learners, in line with Wei's (2011) study which reiterated the benefits of translanguaging of developing confidence amongst learners. Simultaneously the inclusion of L1 in this study is viewed as an asset. L1 as a resource in the 
environment, and as a resource to support learners gain in-depth understanding, aligns with Eloff and Ebersöhn's (2001) view. This view additionally correlates with Scanlan (2007) who correspondingly associates the asset-based perspective to language learning making a claim that L1 should be recognized as a fundamental strength.

"So, I think it would be very nice if the CD can have the Sepedi or the Zulu and other languages in there so when they doing the listening and speaking assessment, it plays in all the languages that would work better"

The translated audio recordings provided a scaffold between the teacher and the learner and this mediated a process of learning and teaching to take place where language barriers exist in line with Vygotsky's (1962) approach of including mediation and scaffolding. The use of technology facilitated the translanguaging practice. Mays (2019) encouraged technology as a resource in diverse settings for learning and teaching to take place. Furthermore, Mays (2019b, p. 141) additionally states that technology can "be used during the process of teaching and learning to address barriers to learning”. Research confirms that L1 needs a space in the educational environment so that learners can scaffold their learning (Hillman et al. 2019) by firstly understanding the content being taught to them through their L1 (Omidire 2019b), and secondly allowing learners to navigate their learning by not relying fully on L1 but rather using it as a mediator to accommodate their learning experience (Hillman et al. 2019; Omidire 2019b). This rationale is featured from the findings of this study where multiple languages afforded a more holistic approach to learning and teaching.

\subsubsection{Valuing L1 in the classroom facilitates better understanding}

- "But I saw learners understand because when that person was speaking in Zulu they were having their story in front of them (neh), they were able to turn around the pages" (IHD, ${ }^{1}$ line 67-69)

- "Same time all of them turned the page, it means they were following."(IHD, line 71-72)

- "Big difference. Home language facilitated better understanding" $\left(\mathrm{OSH}^{2} 3\right.$, Box 6, p.2)

- "The learners enjoyed listening to the audio in their home language." (OSH3, Box 10, p.3)

1 Information obtained during an interview with the Head of department.

2 Observation sheets from teacher 1, 2 and 3. 
During the interviews and from the observation sheets it was clear that L1 allowed learners to understand better because they were simultaneously involved in the process of listening to multiple languages which enhanced their understanding. Tian and Macaro (2012) confirm that learners who receive input in their L1 benefit more than learners who only receive input in one language. Similarly, Gorter and Cenoz (2017) and Omidire (2019b) extend their view on translanguaging as a way to accommodate comprehension skills, which ideally provide translations of the tasks and allow learners to answer content questions in the language in which they feel most comfortable. Refer to Storyboard 2.



Storyboard 2: Understanding content better in L1.

Similarly Storyboard 2 quotes the following:

- "Yes, because I like my home language more than English"

- "I felt happy because now I know what does dove mean in my home language"

- "I liked when the teacher Played the radio and listening to a man who were reading Topo's story in my home language”

During the semi-structured interview, the teachers reported that learners were more engaged in the lessons because L1 guided their understanding by code switching certain words while multiple languages were included, this view echoed from Cummins (2009) who reiterates L1 as a foundation upon which new 
knowledge is built, and Gobincgca (2013) who acknowledged that when L1 was phased in to the education system in South Africa and maintained for 8 years as the primary language of learning, resulted in an improvement of the matriculation results of black learners. Meanwhile Sayer (2013) motivates for L1 and insists on teachers to recognize and utilize learners L1 as teaching tools in line with the translanguaging approach. From the field notes, and teachers interview transcripts, the learners who experienced translanguaging were more involved and engaged in the lessons, and seemed to show more understanding as they raised their hands to answer questions related to the lessons, and they additionally showed more interest in the classroom when compared to the control class where there was no L1 present. The above ties in with Atkinson et al.'s (2000), view that SCT creates a learning environment made up of interaction between teachers, learners and tasks to make available opportunities for learners to build their own understanding during interaction with others. Similar findings emerged from Rivera and Mazak (2016) who shared that by integrating L1, learners enhanced greater sense of ownership within the learning process and fostered a stronger sense of identity. Similarly, Omidire (2019b) linked L1 inclusion to learners improved self-esteem, self-efficacy and enablement.

Furthermore, translanguaging practice was observed by the teachers who reported during the semi-structured interviews and in their observation sheets that the learners were listening to the lesson orally and following the text visually leading them to answer the questions related to the comprehension text and seemed to have a better understanding of the text. This correlates with the views of Lewis et al. (2012) and Mgijima and Makalela (2016) who express translanguaging as the intentional alternating of the language of input and output during a lesson, to allow learners to think and express their ideas in either language in which they feel comfortable. Translanguaging strategies had a positive effect on the learners as they experienced being in a safe environment, and L1 facilitated better understanding, and teachers' enthusiasm facilitated a smooth administration of the support strategy. This ideally falls in line with Baker's (2011) educational advantages.

\subsection{Constraints of using translanguaging}

The constraints identified during the interviews, observation sheets from the teachers, storyboards and field notes include, language complexities, participants' views related to L1; limited resources and time constraints; teachers insufficient training to teach in multilingual classrooms and existing socio-economic factors. 


\subsubsection{Language complexities and contrary views related to L1}

From the teachers' observation sheets and from a few learners' storyboards, the translated recordings of IsiZulu posed with some difficulties when it was translated from English, where some difficult words were present. "No, my home language is kind of difficult sometimes to understand" (Excerpt from a storyboard)

Similar findings were outlined by Mgijima and Makalela's (2016) study, where scholars similarly expressed that another L1 in Africa, namely IsiXhosa also being complicated and did not simplify the learners understanding completely. Some learner's viewpoints from the storyboards elicited contradictory views where on the one hand they appreciated L1 to be incorporated into classrooms but at the same time expressed that they also understood the content in English. "I felt very happy. Other people they don't feel happy because they don't like their home language" (Excerpt from a storyboard)

Strauss (2016) draws attention to this view by identifying parents' views of adopting an approach to rather have their children be taught through the medium of English, and eliminating L1 entirely as a resource within African languages. This type of scepticism was documented by Parmegiani and Rudwick (2014). Their argument is voiced through a different angle explaining that learners were not comfortable using their L1 in an academic setting due to the lack of opportunity in their schooling years which did not allow them to develop strong academic literacy skills in their L1. Similar findings resonated from García and Wei (2014) who assert that the minority language does not compete with the majority language and that some parents seem to want their children to learn in an English language school from Grade 1 (Nel et al. 2012), resulting in language challenges due to English not being their L1 (Rossi and Stuart 2007). Additionally, past historic ideologies found that parents in rural areas requested the school to teach their children in English, because they viewed it as the only common language spoken by most South Africans (Moodley et al. 2017).

It would seem that previous language policies have rippled into the downfall for many learners who are firstly very reliant on their L1, and secondly, L1 falls away from Grade 4 onwards when English is embraced as the language of learning and teaching in public schools which affects learning outcomes as displayed in the findings above (Makaleka 2018a). This causes learners to experience a lack of understanding of learning content because L1 is not included in their classrooms any longer, impacting learning outcomes.

A small percentage of learners displayed in their storyboards that they felt left out during the support strategies, and this was also reported in the interview where one teacher said that they experienced boredom, because their particular L1 was 
not translated and audio recorded. "I felt bored, because I am not a Zulu and Sepedi, I want it in Venda”. (Excerpt from a storyboard)

- There are two or three that don't understand any of the languages because they are from Zimbabwe or Pakistan or something like that but majority of the learners are from here and they understand. (IT1, line 150-153)

This aligns with Ngcobo et al. (2016) who expressed that such learners who are not proficient in African languages in class may feel left out.

\subsubsection{Limited resources and time constraints}

The lack of resources at both research sites shared commonalities during the interviews, field notes and from the observation sheets of having overcrowded classrooms resulting in a shortage of furniture like tables and chairs, and a shortage of teachers. Additionally, educational resources such as not having a curriculum to cater for multilingualism, as well as not having enough dictionaries for the learners to utilize during the English lessons, impeded on the learning and teaching practices. Furthermore, financial constraints leading to the government and the respective departments responsible for funding basic resources to the schools was questioned at both research sites by the school principal, HOD and the teachers in separate discussions.

- "It is good to teach in multilingualism but takes more time and needs more resources.” (OSH3, Box 15, p. 4)

- "It is a good venture though time consuming and expensive.”(OSH3, Box 32, p. 8)

- "It's good but a lot of translation has to be done, and might be very expensive." (OSH3, Box 40, p. 10)

- “... another problem is that they don't have dictionaries like we are overcrowded so you can't have all the dictionaries for 103 learners the learners who are not shy will come and ask mam explain me this word, most of the time I don't like to explain.” (IHD, line 135-140)

Mokolo (2014), Myende (2014), and Gobingca (2013) shed light that many schools in township areas are often characterized as being under-resourced and not having basic facilities such as sufficient classrooms, or facilities such as electricity and water. These schools often lack furniture like desks and chairs for the learners, classrooms are overcrowded and the teacher: learner ratio is concerning. This concern is predominant in literature where similar trajectories are identified from the works of Ebersöhn, et al. (2017) who explains the limited access to adequate 
electricity, transportation and education as significant challenges which affect learning outcomes and is substantially identified in my study.

Moreover, educational resources to support multilingualism seemed like a distant concern in these schools, despite the urgent need campaigned from the teachers to include educational resources like English text books with translated CD's in the different L1's to scaffold learning, and providing additional resources like translated L1's. Recommendations to adjusting the curriculum to include diverse languages was motivated from the school principal to the teachers in the classrooms realizing the urgency of such support strategies to accommodate learners in multilingual classrooms. This is in line with (Makalela 2015b) view of an overwhelming and dominating curriculum. However, during the semi-structured interviews, teachers are mindful that such initiatives are extremely time consuming and expensive especially when one has to translate all learning content and the country already have impeding financial constraints. There is agreement in research that most schools are under-resourced and are not equipped to cater for learners in multilingual classrooms (Rassool and Edwards 2010).

The inclusion of translanguaging support strategies were linked to time constraints, in line with Palmer (2009) who addresses time constraints as schools adhering to traditional language boundaries and segmenting language lessons to certain times a day. The teachers' view of including multiple languages to guide the learning experiences can impact on the assessment criteria stipulated by the department of education (which does not cater for multilingual learning) which creates a sense of apprehension where they cannot meet deadlines. Teachers need more support and better preparation to make meaningful changes in multilingual classrooms.

Omidire (2019a) agrees with this study and reinforces that teachers do not have sufficient training to deal with second language learning nor can they adjust the curriculum in support of their teaching due to time constraints especially in large classrooms (Khong and Saito 2013). Additionally, teachers find it difficult to include support strategies for their learners as there are insufficient resources at many of the schools (Balfour et al. 2008) which influence learners' schooling in line with similar findings documented in my study.

\subsubsection{Teachers insufficient training to teach in multilingual classrooms}

It is apparent from the semi-structured interviews that all the teachers involved in multilingual classrooms are aware of the literacy challenges learners are currently experiencing within the South African context. However, they are even more frustrated by the fact that they are unable to provide these learners with knowledge and skills which seem to be out of their depth and capabilities. Nagy (2018) 
similarly states that teachers are challenged when they have to utilize multiple languages in the classroom to promote learning on the basis that they have only been trained according to monolingual language norms that discard the use of other languages in class.

- "very difficult, so if the teacher is able to parallel teach, and know the language, obviously you need re-skilling and up-skilling of teachers.” (IP, ${ }^{3}$ line 170-171, p. 6)

- "It is a good idea but an expensive exercise to African governments which are already poor.” (OSH3, Box 48, p. 12)

- “... and I don't know if our government has that type of money” (IP, line 173. p. 6)

The school principal acknowledged that for multilingualism to be accepted at schools and given the educational benefits of guided support, requires "reskilling and upskilling of teachers". Teacher training is imperative and recognized as a need by the school principal, who subsequently rationalized that the school governing body lack funds to initiate training for teachers. In line with this view, Naiker et al. (2014) agree that the school principal's leadership is an important resource for any school and the school principal should establish partnerships with the teachers by mentoring them and providing support. Similarly, Myende and Chikoko (2014), confirm that such partnerships allow teachers to be regarded as assets. On that note, the assets recognized in a school according to Ebersöhn and Eloff (2006) are the leadership capacity in teachers, learners, parents as well as books, videos, audiotapes, furniture, blackboards, as well as the peer group support of diverse learners with different L1's.

On that insight, Nel and Müller (2010) recommend that teachers should receive training to equip them to teach English as a second language, as well as general support to teach the learners effectively. $\mathrm{Wu}$ (2018) additionally states that school policy makers and administrators should take action, such as adjusting policies properly, supporting teachers' professional development, and establishing a comfortable and positive environment where learners and teachers may feel less anxiety and become more confident.

It would seem that learning and teaching in multilingual settings needs a shift in focus within the academic sphere to accommodate diversity. Omidire (2019a) summarizes the teachers' position in multilingual classrooms by stating

that many teachers are ill prepared to deal with learners who speak English as a second language. Teachers have insufficient training to handle second language learning and to

3 Interview with school principal. 
adjust the curriculum in support of their teaching. To teach second language learners properly, more time is needed to work effectively with them. (p. 8)

Teacher training is not sufficiently recognized in African schools.

\subsubsection{Existing socio-economic factors}

South Africa has a multitude of socio-economic challenges coupled with poverty and unemployment (Spaull 2013), overcrowded classrooms, as well as teachers whose L1 is different from that of the learners (Ticheloven et al. 2019). The teachers identified socio-economic factors impeding on learning. Below are some excerpts:

“yes, township areas they come from far places, it's not only Atteridgeville, it's really far like Shoshanguwe and they leave early, they leave like at 4am in the morning, they here by 6am, half six by then they tired, they hungry, and I think that also plays an important part in their development." (IT, ${ }^{4} 1$ line $314-318$ )

- and another challenge is that our children come from they come from squatter camps there is no electricity and they will tell you did not have electricity to do homework or to study all those excuses so we intervene 30 min before school knocks off to at least try to help them I will give them revision and take them to the library to help them study, to do intervention." (IHD, line 240-249)

- "On an average there are 42 learners in a classroom." (IP, line 57, p.4)

- “...some of the challenges overcrowding, so sometimes it's difficult to give individual attention for the learners” (IT3, line 26-27)

Cognisant to these challenges, the teachers support the idea of embracing translanguaging as a support strategy to guide the learners to develop literacy skills by acknowledging the need for L1 to be included into the school curriculum, in line with the asset-based approach which identifies with the challenges faced in the educational sphere. Myende (2014) similarly, suggests that to overcome these problems, schools need to develop strategies such as assessing their existing assets and mobilising them accordingly.

\subsection{Significance and limitations}

Insights into the use of translanguaging to inform our knowledge of learning and teaching in multilingual classrooms is possible when one can identify the enablers

4 Interview with teacher 1, 2 and 3. 
and the constraints of using translanguaging to support learning in primary school classes. Understanding the experiences of the learners and the teachers in multilingual contexts and determining the teachers' perceptions regarding the use of translanguaging as a support strategy for learning in multilingual contexts is necessary. Findings from this study outline the positive impact of translanguaging. Learners involved in the study indicated a need for more translanguaging lessons and acknowledged that translanguaging informed their understanding. In addition, most learners experienced positive feelings associated with L1 when L1 was included in the lesson. There was agreement amongst both the learners and the teachers regarding the use of the translated audio recordings. Firstly, the recordings facilitated the use of L1 in the classroom. Secondly, the translated audio recordings took the place of guided mediation and added value to the translanguaging approach. Lastly, the translated audio recordings provided support and were recognised as a valuable resource for both the learners and the teachers.

The limitations of the study included the inability of the researchers to include more than two languages. This resulted in a couple of learners per class who felt excluded in the experience and process because their L1s was not part included in the translated texts. In addition, there was limited time for the lessons.

\section{Conclusion}

The purpose of this study was to explore the enablers and constraints of using learners' home languages as a support strategy to facilitate learning and teaching within multilingual classrooms and thereby developing both L1 and the English language within the framework of additive multilingualism. The study sought to gain a comprehensive understanding of how teachers manage the process of translanguaging in their classrooms.

Cultural and linguistic diversity is commonplace in South African classrooms leading to language challenges for learners torn between their L1 and the language of instruction in the classrooms. This study used translanguaging as an approach to understand the enablers and constraints of using multiple languages for learning in primary school classes. Findings from this study suggest that the enablers were, a non-threatening environment that supported the learners and made them feel accepted. In addition, the teachers' positive attitudes towards translanguaging made the support strategy easier to administer and learners more receptive to exploring new strategies. Furthermore, the availability of the translated audio recordings of learners' L1s as a resource and the inclusion of L1 in the lessons enabled the success of the lessons as indicated by the learners and their teachers. The constraints of using translanguaging to support learning and 
teaching practices in multilingual classrooms included the extent of language complexities and contrary views relating to L1. The findings also show that the lack of resources in schools and lesson time constraints are considered a hinderance to the implementation of translanguaging as a support strategy in primary classes. It was also noted that insufficient training to teach in multilingual classrooms and existing socio-economic factors also constitute constraints.

A recommendation emanating from the findings of this study is that significant investment in pre-service teacher education to raise awareness on the importance of integrating learners' L1s into lessons is required. The importance of learning in a non-threatening positive environment and creating the right attitude towards learners' home languages and culture have to be incorporated into the training. Teachers' attitudes matter. The training should further focus on effective pedagogy for teaching linguistically diversity learners and providing teachers with techniques for working in multilingual classrooms. Directed teachers' professional development programmes have to be initiated to support in-service teachers' multilingual contexts. Policy should focus on a dynamic and transformative process of structuring the different L1's through technological processes by building on their existing methods. Where they currently provide CDs of the learning content in their textbooks, they can extend this practice by translating all learning content into the different L1's and provide learners with ways in which to access this. By using simple tools like ear phones where learners can listen to learning content in the language of their choice can create opportunities of being accommodated in a multilingual world. Future research should be longitudinal and focus on the impact of translanguging on learners' achievement over time across the curriculum.

\section{References}

Atkinson, Robert K., Sharon J. Derry, Alexander Renkl \& Donald W. Wortham. 2000. Learning from examples: Instructional principles from the worked examples research. Review of Educational Research 70(2). 181-214.

Baker, Colin. 2011. Foundations of bilingual education and bilingualism, 5th ed. Clevedon, UK: Multilingual Matters.

Balfour, Robert, Claudia Mitchell \& Relebohile Moletsane. 2008. Troubling contexts: Toward a generative theory of rurality as education research. Journal of Rural and Community Development 3(3). 100-111.

Bialystok, Ellen. 2018. Bilingual education for young children: Review of the effects and consequences. International Journal of Bilingual Education and Bilingualism 21(6). 666-679.

Blackledge, Adrian \& Angela Creese. 2010. Multilingualism: A critical perspective. London: Continuum. 
Canagarajah, Suresh. 2011. Translanguaging in the classroom: Emerging issues for research and pedagogy. Applied Linguistics Review 2. 1-27.

Catalano, Theresa \& Edmund T. Hamann. 2016. Multilingual pedagogies and pre-service teachers: Implementing language as a "resource" orientation in teacher education programs. Bilingual Research Journal 39(3-4). 263-278.

Cenoz, Jasone \& Durk Gorter. 2017. Minority languages and sustainable translanguaging: Threat or opportunity? Journal of Multilingual and Multicultural Development 38(10). 901-912.

Childs, Margie. 2016. Reflecting on translanguaging in multilingual classrooms: Harnessing the power of poetry and photography. Educational Research for Social Change 5(1). 22-40.

Cole, Michael \& Sheila R. Cole. 2001. The development of children, 4th ed. New York: Scientific American Books.

Cummins, Jim. 2009. Multilingualism in the English-language classroom: Pedagogical considerations. Tesol Quarterly 43(2). 317-321.

Duarte, Joan 2019. Translanguaging in mainstream education: A sociocultural approach. International Journal of Bilingual Education and Bilingualism 22(2). 150-164.

Ebersöhn, Lesel \& Irma Eloff. 2006. Identifying asset-based trends in sustainable programmes which support vulnerable children. South African Journal of Education 26(3). 457-472.

Ebersöhn, Lesel, Tilda Loots, Ruth Mampane, Funke Omidire \& Marlize Malan-Van Rooyen. 2017. Age-old care and support practices in Southern Africa functioning robustly as sophisticated social technology interventions. Journal of Community Psychology 45. 727-747.

Eloff, Irma \& Liesel Ebersöhn. 2001. The implications of an assets-based approach to early intervention. Perspectives in Education 19(3). 147-156.

Ferreira-Meyers, Karen Aline Francoise \& Fiona Horne. 2017. Multilingualism and the language curriculum in South Africa: Contextualising French within the local language ecology. Stellenbosch Papers in Linguistics Plus 51. 23-40.

García, Ofelia. 2009a. Bilingual education in the 21st century: A global perspective. Hoboken, NJ: Wiley-Blackwell.

Garcia, Ofelia. 2009b. Emergent bilinguals and TESOL: What's in a name? Tesol Quarterly 43(2). 322-326.

García, Ofelia. 2019. Translanguaging: A coda to the code? Classroom Discourse 10(3-4). 369-373.

García, Ofelia \& Camila Leiva. 2014. Theorizing and enacting translanguaging for social justice. In A. Blackledge \& A. Creese (eds.), Heteroglossia as practice and pedagogy, 199-216. Netherlands: Springer, Volume 20 of the series Educational Linguistics.

García, Ofelia \& Li Wei. 2014. Translanguaging: Language, bilingualism and education. London: Palgrave Macmillan.

García, Ofelia, Susana Ibarra Johnson \& Kate Seltzer. 2017. The translanguaging classroom: Leveraging student bilingualism for learning. Philadelphia, PA: Caslon.

Gobingca, Zameka. 2013. Strategies employed by primary school teachers to support nonIsiXhosa speaking learners in Mthatha Education District. Alice, Eastern Cape: University of Fort Hare Master's dissertation.

Gorter, Durk \& Jasone Cenoz. 2017. Language education policy and multilingual assessment. Language and Education 31. 231-248.

Guillemin, Marilys. 2004. Understanding illness: Using drawings as a research method. Qualitative Health Research 14(2). 272-289.

Hayes, Nicky. 2011. Doing psychological research. New York: Open University Press. 
Hillman, Sara, Keith M. Graham \& Zohreh R. Eslami. 2019. Teachers' translanguaging ideologies and practices at an international branch campus in Qatar. English Teaching \& Learning 43(1). 41-63.

Ismaili, Merita. 2015. Teaching English in a multilingual setting. Procedia-Social and Behavioral Sciences 199. 189-195.

Jaspers, Jürgen. 2018. The transformative limits of translanguaging. Language \& Communication 58. 1-10.

Khong, Thi Diem Hang \& Eisuku Saito. 2013. Challenges confronting teachers of English language learners. Educational Review 66(2). 210-225.

Kleyn, Tatyana \& Ofelia García. 2019. Translanguaging as an act of transformation restructuring teaching and learning for emergent bilingual students. In L. C. de Oliveira (ed.), The Handbook of TESOL in K-12, 70-82. Hoboken, NJ: John Wiley \& Sons.

Kretzmann, John P. \& John L. McKnight. 1993. Building communities from the inside out: A path towards finding and mobilizing community assets. Chicago: ACTA Publications.

Lasagabaster, David \& Ofelia García. 2014. Translanguaging: Towards a dynamic model of bilingualism at school. Cultura y Educación 26(3). 557-572.

Leask, Marisa Claudia. 2019. Enablers of teaching language for learning in multilingual classrooms. In M. F. Omidire (ed.), Multilingualism in the classroom: Teaching and learning in a challenging context. Cape Town: Juta \& Co.

Lewis, Gwyn, Bryn Jones \& Colin Baker. 2012. Translanguaging: Developing its conceptualisation and contextualisation. Educational Research and Evaluation 18(7). 655-670.

Lwanga-Lumu, Joy Christine. 2020. Intercultural Communicative Component (ICC) in the English Second Language (EL2) Curricula: Trends and challenges of transformation in South Africa (SA) and the global world. Journal of Intercultural Communication 20(1). 1-16.

Madiba, Mbulungeni. 2012. Language and academic achievement: Perspectives on the potential role of indigenous African languages as lingua Academia. Per Linguam 28(2). 15-27.

Makalela, Leketi. 2015a. Translanguaging as a vehicle for epistemic access: Cases for reading comprehension and multilingual interactions. Per Linguam 31(1). 15-29.

Makalela, Leketi. 2015b. Breaking African language boundaries: Student teachers' reflections on translanguaging practices. Language Matters 46(2). 275-292.

Makalela, Leketi (ed.). 2018a. Shifting lenses: Multilanguaging, decolonization and education in the global South. Cape Town: Centre for Advanced Studies of African Society (CASAS).

Makalela, Leketi. 2018b. Community elders' narrative accounts of ubuntu translanguaging: Learning and teaching in African education. International Review of Education 64(6). 823-843.

Mays, Tony John. 2019. Using technology as a resource for teaching and learning in multilingual classrooms. In M. F. Omidire (ed.), Multilingualism in the classroom: Teaching and learning in a challenging context. Cape Town: Juta \& Co.

Mgijima, Vukile Desmond \& Leketi Makalela. 2016. The effects of translanguaging on the biliterate inferencing strategies of fourth grade learners. Perspectives in Education 34(3). 86-93.

Mokolo, Mokgalakane Frans. 2014. An investigation into patterns of translanguaging in classrooms in the foundation phase in a primary school in the Limpopo province. South Africa: University of Limpopo Master's dissertation.

Moodley, Pathmanathan, Alta Kritzinger \& Bhme Vinck. 2017. Comparison of educational facilitation approaches for Grade R English additional language learning in Mpumalanga. South African Journal of Education 34(2). 1-17. 
Moody, Stephanie, Mahjabin Chowdhury \& Zohreh Eslami. 2019. Graduate students' perceptions of translanguaging. English Teaching and Learning 43. 85-103.

Mwinda, Nangura \& Christa Van der Walt. 2015. From 'English-only' to translanguaging strategies: Exploring possibilities. Per Linguam: Journal of Language and Learning 31(3). 100-118.

Myende, Phumlani Erasmus. 2014. Improving academic performance in a rural school through the use of an asset-based approach as a management strategy. Bloemfontein, South Africa: University of the Free State Unpublished Ph.D. thesis.

Myende, Phumlani Erasmus \& Vitallis Chikoko. 2014. School-University partnership in a South African rural context: Possibilities for an asset-based approach. Journal of Human Ecology 46(3). 249-259.

Nagy, Tünde. 2018. On translanguaging and its role in foreign language teaching. Acta Universitatis Sapientiae, Philologica 10(2). 41-53.

Naiker, Inbanathan, Vitallis Chikoko \& Siphiwe Eric Mthiyane. 2014. Does mentorship add value to in-service leadership development for school principals? Evidence from South Africa. The Anthropologist 17. 421-431.

Natri, Teija \& Anne Räsänen. 2015. Developing a conceptual framework: The case of MAGICC. In J. Jalkanen, E. Jokinen \& P. Taalas (eds.), Voices of pedagogical development - expanding, enhancing and exploring higher education language learning, 85-102. Dublin: Researchpublishing.net.

Nel, Norma \& Helēne Müller. 2010. The impact of teachers' limited English proficiency on English second language learners in South African schools. South African Journal of Education 30(4). 635-650.

Nel, Norma, Mirna Nel \& A. Hugo. 2012. Inclusive education: The necessity of providing support to all learners. In M. N. Nel \& A. Hugo (eds.), Learner support in a diverse classroom, 3-24. Pretoria: Van Schaik.

Ngcobo, Sandiso, Nobuhle Ndaba, Bulelwa Nyangiwe, Njabulo Mpungose \& Rafiq Jamal. 2016. Translanguaging as an approach to address language inequality in South African higher education: Summary writing skills development. Critical Studies in Teaching and Learning 4(2). 10-27.

Nieuwenhuis, Jan. 2010. Introducing qualitative research. In K. Maree (ed.), First steps in research. Pretoria: Van Schaik.

Oihana, Leonet, Jasone Cenoz \& Durk Gorter. 2020. Developing morphological awareness across languages: Translanguaging pedagogies in third language acquisition. Language Awareness 29(1). 41-59.

Omidire, Margaret Funke. 2019a. Experiencing language challenges in a rural school: Implications for learners' life aspirations. Early Child Development and Care (ECDC), Special Issue. 1-19.

Omidire, Margaret Funke. 2019b. Embracing multilingualism as a reality in classrooms: An introduction. In M. F. Omidire (ed.), Multilingualism in the classroom: Teaching and learning in a challenging context. Cape Town: Juta \& $\mathrm{Co}$.

Owen-Smith, Margie. 2010. The language challenge in the classroom: A serious shift in thinking and action is needed. Focus 56. 31-37.

Palmer, Deborah K. 2009. Code-switching and symbolic power in a second-grade two-way classroom: A teacher's motivation system gone awry. Bilingual Research Journal 32(1). 42-59.

Parmegiani, Andrea \& Stephani Rudwick. 2014. IsiZulu-English bilingualisation at the University of KwaZulu-Natal: An exploration of students' attitudes. In L. Hibbert \& C. van der Walt (eds.), 
Multilingual universities in South Africa: Reflecting society in higher education, 107-122. UK: Multilingual Matters.

Paxton, Moragh Isobel Jane. 2009. It's easy to learn when you using your home language but with English you need to start learning language before you get to the concept: Bilingual concept development in an English medium university in South Africa. Journal of Multilingual and Multicultural Development 30(4). 345-359.

Phipps, Alison. 2019. Decolonising multilingualism: Struggles to decreate. Bristol, UK: Multilingual Matters.

Rassool, Naz \& Viv Edwards. 2010. Multilingualism in African schools: Constraints and possibilities. Language and Education 24(4). 277-281.

Rivera, Adrian J. \& Catherine M. Mazak. 2017. Analyzing student perceptions on translanguaging: A case study of a Puerto Rican university classroom. HOW Journal 24(1). 122-138.

Rossi, June \& Anita Stuart. 2007. The evaluation of an intervention programme for reception learners who experience barriers to learning and development. South African Journal of Education 27(1). 139-154.

Sarker, Mohammad Faysal. 2019. Zone of proximal development. International Journal of Advancements in Research \& Technology 8(1). 27-46.

Sayer, Peter. 2013. Translanguaging, TexMex, and bilingual pedagogy: Emergent bilinguals learning through the vernacular. Tesol Quarterly 47. 63-88.

Scanlan, Martin. 2007. An asset-based approach to linguistic diversity. Focus on Teacher Education 7(3). 3-5, 7.

Spaull, Nicholas. 2013. South Africa's education crisis: The quality of education in South Africa 1995-2011. Johannesburg, South Africa: Centre for Development and Enterprise.

Strauss, Stuart. 2016. Code-switching and translanguaging inside and outside the classroom:Bi-/ multilingual practices of high school learners in a rural Afrikaans-setting. South Africa: University of Stellenbosch Master's dissertation.

Tian, Lili \& Ernesto Macaro. 2012. Comparing the effect of teacher code switching with English only explanations on the vocabulary acquisition of Chinese university students. Language Teaching Research 16(3). 367-391.

Ticheloven, Anouk, Elma Blom, Paul Leseman \& Sarah McMonagle. 2019. Translanguaging challenges in multilingual classrooms: Scholar, teacher and student perspectives. International Journal of Multilingualism. https://doi.org/10.1080/14790718.2019.1686002.

Turner, Marianne. 2017. Integrating content and language in institutionally monolingual settings: Teacher positioning and differentiation. Bilingual Research Journal 40(1). 70-80.

Vaish, Vaniti \& Aidil Subhan. 2015. Translanguaging in a reading class. International Journal of Multilingualism 12(3). 338-357.

Velasco, Patricia \& Ofelia García. 2014. Translanguaging and the writing of bilingual learners. Bilingual Research Journal 37(1). 6-23.

Vygotsky, Lev. 1962. Thought and language (1934). Trans Eugenia Hanfmann \& Gertrude Vokar. Cambridge, MA: MIT Press.

Wei, Li. 2011. Moment analysis and translanguaging space: Discursive construction of identities by multilingual Chinese youth in Britain. Journal of Pragmatics 43(5). 1222-1235.

Williams, Cen. 1994. An evaluation of teaching and learning methods in the context of bilingual secondary education. Bangor, UK: University of Wales Unpublished doctoral thesis.

Wu, Sipeng. 2018. Using the first language in the second language classroom. New Zealand: University of Victoria Master's dissertation. 